\title{
Renewable generation and demand response integration in micro-grids: development of a new energy management and control system
}

\author{
Carlos Álvarez-Bel, IEEE Member, Guillermo Escrivá-Escrivá, Manuel Alcázar-Ortega \\ Institute for Energy Engineering \\ Universitat Politècnica de València \\ Valencia, Spain \\ calvarez@die.upv.es
}

\begin{abstract}
The aim of this research resides in the development of an energy management and control system (EMCS) to control a micro-grid based on the use of renewable generation and demand resources to introduce the application of demand response concepts to the management of micro-grids in order to effectively integrate the demand side as an operation resource for the grid and improve energy efficiency of the elements. As an additional result, the evaluation of reductions in the total amount of $\mathrm{CO}_{2}$ emitted into the atmosphere due to the improvement of the energy efficiency of the system is assessed.
\end{abstract}

Keywords- Load Control; Demand Response Resources; Load Management; Renewable Generation; Energy Efficiency

\section{NOMENCLATURE}

$C_{g-\mu}^{i}$, cost of power produced by generation resources of the micro-grid in the hour $i$, in $€ / \mathrm{h}$

$C_{f-\mu}^{i}$, fix unitary cost of power produced by generation resources of the micro-grid in the hour $i$, in $€ / \mathrm{h}$

$C_{v-\mu}^{i}$, variable unitary cost, which includes fuel cost and any other variable cost directly related to the amount of power produced by generation resources of the micro-grid in the hour $i$, in $€ / \mathrm{kWh}$

$C_{c-\mu}^{i}$, quadratic coefficient, which includes any variable cost related to quadratic power produced by generation resources of the micro-grid in the hour $i$, in $€ /(\mathrm{kW})^{2} \cdot \mathrm{h}$

$P_{g-\sigma}^{i}$, power generated by resources of the micro-grid, including renewable and conventional generation as well as power storage devices and demand response resources in the hour $i$, in $\mathrm{kW}$ $€ / \mathrm{h}$

$C_{g-g}^{i}$, cost of power demanded from the grid in the hour $i$, in

$C_{f-g}^{i}$, fix unitary cost of power demanded from the grid related to the value of contracted power in the hour $i$, in $€ / \mathrm{h}$

$C_{v-g}^{i}$, price of electricity in the hour $i$, in $€ / \mathrm{h}$

$P_{g-g}^{i}$, power demanded from the grid in the hour $i$, in $\mathrm{kW}$ $\mathrm{kW}$

$P_{D}^{i}$, total power demanded by customers in the hour $i$, in $€ /$ day

$C_{D}$, total daily cost of electricity to be paid by customers, in

$A E_{s}$, avoided emissions into the atmosphere due to the application of efficiency and management actions, in tonCO $\mathrm{CO}_{2}$

$f e_{i}$, emission factor in the period $i$ ( $i$ is equal to 1 for on-peak, 2 for shoulder and 3 for valley period), in ton $\mathrm{CO}_{2} / \mathrm{MWh}$

\section{INTRODUCTION}

Electricity markets in developed countries, where new regulation pursues for stricter quality levels of supply [1], have been some years ago involved in a liberalization process. In this context, the electricity demand is gradually rising and, as a consequence, the risk of electricity grids overload also increases. This fact enhances the possibility of stability problems, which could put in risk the quality of the service given to customers [2].

The building of new transmission and distribution lines usually produces social rejection and, sometimes, it comes into conflict with environmental issues. For that reason, lines at the present do not grow and are not reinforced according to the rising of the power demand.

According to the existing capacity of the grid, the amount of energy able to be transmitted in a constant way during 24 hours would be higher than twice the current value, at the same time that the stability of the grid would be also higher [2]. Taking into account these aspects, it seems clear that a more efficient and rational use of the grid is considered as the most suitable solution.

However, as the load of the system is not constant along of the time and the power demanded and generated must be balanced at anytime, it is possible to create a scenario where small generators and other devices able to store energy are strategically located around the power system. This new 
scenario allows the grid to transmit a more stable load, while power losses are reduced as generators are near to consumers.

This new concept of distributed generation means a novel approach to the management of electricity systems that, conversely to the traditional configuration based on large generation plants, resides on the connection to the medium and low voltage grids of small modular generation units, often based on renewable sources (biomass, solar, wind power, diesel, etc.) and other conventional units. Distributed generators together with the energy storage devices, designed as distributed energy resources (DER), constitute a solution to the randomness of renewable energy sources [3-6].

In order to properly use the potential of renewable generation in the distribution grid, generation and energy storage devices must be considered as integral elements of the grid. Each one of these elements must be able to independently react to voltage or frequency variations in order to keep an optimum schedule, providing energy to the highest number of loads as possible [7-10].

The introduction of such models as peer-to-peer and plugand-play for distributed generation devices in the grid is proposed as a mechanism to provide the system with a more flexible configuration. This means that neither change in the grid configuration nor in the control system would be necessary in order to connect generators to the grid. As no centralized control would be used, each generator should manage its reactive power production in order to maintain the local voltage, also having automatic generation control to keep the power balance. Additionally, the system would not be affected by the loss of any of its parts [11-12].

Demand response (DR), understood as the ability of customers to modify their usual consumption profile as a reaction to different electricity prices in different periods of time [13-17] must be considered in order to improve the performance of power systems. Consequently, the control system needs to include the design and implementation of a set of tools that will enable customers to participate as demand services providers for the system, as well as the thecnical coordination and economic settlement of such actions.

Another premise of control for network management is to improve the efficiency of systems involved. Reductions in the load when prices are high, disconnection of unnecessary load, management of devices to improve energy efficiency, etc. are actions to be considered within the overall micro-grid control.

The paper is organized as follows. Section III describes in detail the configuration of the proposed micro-grid, based on the use of an energy management and control system (EMCS). The operation schedule of the proposed system is explained in Section IV, where the case of the Campus of Vera of the Universitat Politècnica de València (UPV) is presented as example where a pilot micro-grid based on the EMCS has been successfully implemented. Section $\mathrm{V}$ is devoted to the economic and environmental evaluation and, finally, some conclusions are shown in Section VI.

\section{CONFIGURATION OF THE MICRO-GRID}

\section{A. General Description}

Micro-grids are small electrical distribution systems that connect multiple customers to multiple distributed sources of generation and storage [18]. This new concept of distributed generation means a novel approach to the management of electricity systems that, conversely to the traditional configuration based on large generation plants, resides on the connection of small modular generation units to the medium and low voltage grids. Renewable generators, together with the energy storage devices, constitute a solution to the randomness of renewable energy sources.

Fig. 1 shows a scheme about the performance of a microgrid based on an EMCS. According to the demand of different types of customers (residential, industrial or commercial), the EMCS can decide whether the power should be acquired from the conventional grid or provided by the generation resources connected to the micro-grid. The source to be used (conventional grid or micro-grid) will be chosen according to the price of energy, so that customers will pay the minimum possible amount of money for the energy they consume.

Generation resources in the micro-grid are not physically connected to the power grid (see Fig. 2) that is an important point of view as most of regulatory barriers are focused on this aspect.

Customers can be supplied by any of the two grids, but the decision is made by the EMCS. This decision must be based on an economic dispatch that enables the EMCS to assess the amount of power to be produced by generation resources in the micro-grid, so that only the difference between this amount and the total demand will be bought to the conventional grid. Consequently, the distributed energy resources only can provide to the customers connected to the micro-grid, but not deliver that power to the conventional grid.

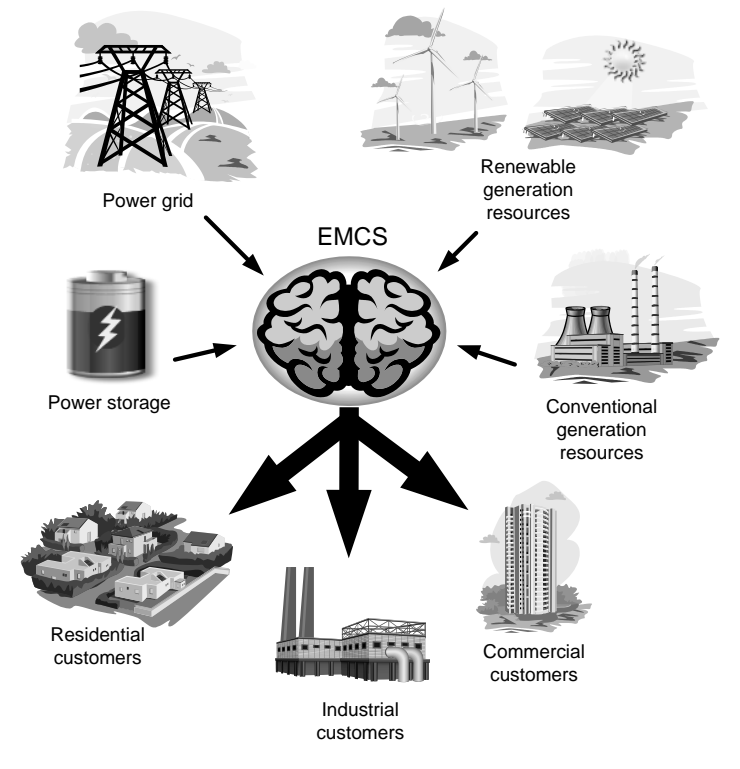

Figure 1. Scheme of a micro-gird 


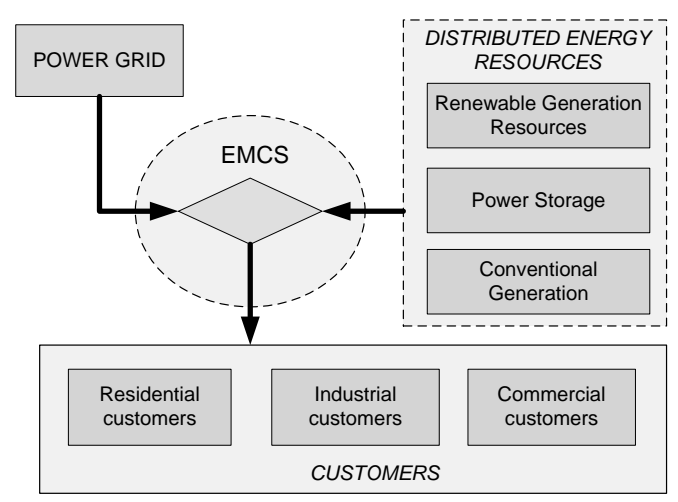

Figure 2. Block diagram of the proposed configuration for a micro-grid based on an EMCS

\section{B. Operation}

Fig. 3 shows the operation schedule for a micro-grid managed by an EMCS, whose working plan is based on three stages:

- Reception Stage. Customers inform the EMCS about the power they forecast to consume for each hour in the time horizon considered (for example, for the next day). At the same time, the EMCS gathers information about the price of energy in the electricity market and the incremental cost of the distributed generation resources able to produce energy for the same period of time.

- Decision Stage. The EMCS perform an economic dispatch for each hour according to the power required by customers and prices of energy coming from the conventional bulk power system and the micro-grid, so that the optimal amount of power to be consumed from each of these sources is properly assessed considering technical restrictions. Consequently, the EMCS order to the generation resources of the micro-grid to produce just the amount cheaper than the one coming from the grid.

- Verification Stage. Once the generation resources from the micro-grid are supplying the committed energy and the rest of power to satisfy the total demand is flowing from the grid, the EMCS must measure and verify that the amount of power from each source is properly being delivered in order to settle the interchange

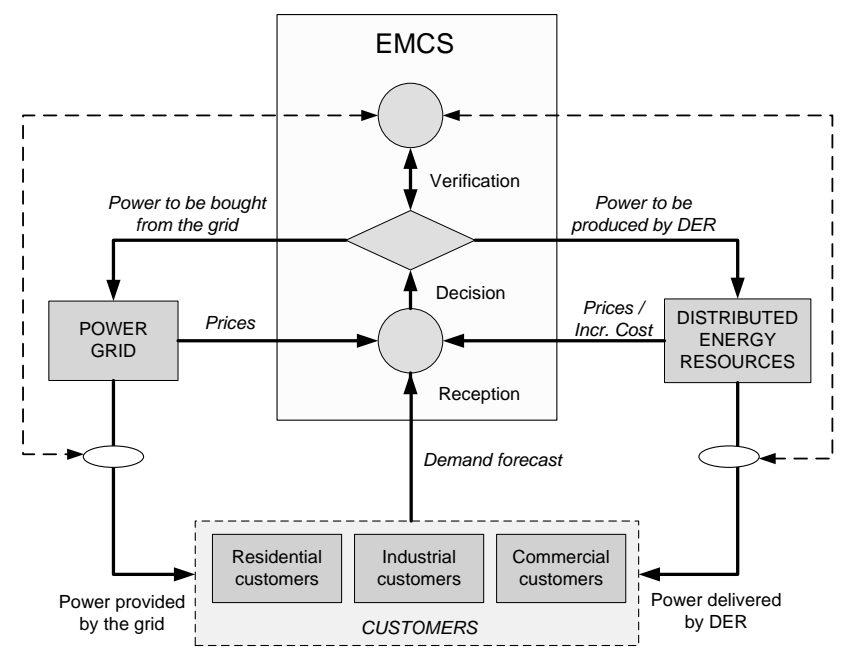

Figure 3. Outline of operation of a micro-grid based on an EMCS

\section{TECHNICAL ISSUES: HOW DO THEY JOIN TOGETHER? THE UPV EMC SYSTEM}

The energy management and control system (EMCS) presented in this article shares some characteristics with other building management systems (BMS) since technological solutions based on distributed intelligent processors are commonly used. There are many commercial brands, such as Honeywell, Siemens, Johnson controls, etc., that provide these functionality. Nevertheless, existing control systems present several constraints (specific software not adaptable, price, specific hardware to be used, etc.). This is why it is necessary to raise innovative designs and introduce a new EMCS with additional developments. The proposed EMCS includes the following general features [19]:

- User interaction with the system is set through a web platform, which avoids the need of installing specific software at each work station. The web has been developed to enable the access to different user profiles. The system database is implemented in SQL Server that provides a great functionality and has no major technical constraints to the system.

- System architecture uses TCP-IP protocol, so that it is not necessary to perform specific wiring to implement the system. The commercial device chosen to implement the network is Telemecanique ETG100 Ethernet gateway.

- The system performs and stores electrical magnitudes measurements from the different facilities. The EMCS provides a specific application for data acquisition, generating an easy-to-use and extend database. Besides, the software considers anomalous situations such as lack of communication with measurement devices, making a posterior available data treatment. Therefore, it is an important improvement with respect to current BMS which, at the moment, are not gathering energy consumption measurements, or if doing so, they are not storing and treating the energy data adequately. The commercial power device used is 
the Power Meter 710 Merlin Gerin. Current transformers (I1A / 5A) selected for the particular point are required.

- It is independent of users' geographical dispersion since it enables management by all users from only just one control center.

- Since the EMCS has been entirely developed at UPV, from its architecture to the applications, it provides with a huge flexibility to the system, thereby making easier the maintenance and updating of the whole system. BMSs available in the market have specific applications developed by commercial trademarks, but they can not be extended or adapted to the specific needs of new goals. With the comprehensive EMCS development of the system, any current or future need could be implemented, as ones previously mentioned.

- Economic reasons also enhance the need for EMCS development. Commercial control systems are characterized by the number of points to be controlled and depending on the available applications. Therefore, it is possible that certain desired applications might need to acquire new licenses at a high cost for exceeding the number of available points.

Three aspects of the EMCS can be deeply discussed: management of the energy supply, demand response features and operation of the micro-grid.

\section{A. Energy supply}

In order to perform the management of the energy supply, the EMCS considers the following aspects:

- Specific applications such as energy consumption surveillance, consumption control, and utilization analysis categorized in periods, as mentioned at the beginning of this section, have been developed.

- Automatic actions (demand response and rescheduling actions) necessary to achieve greater efficiency have been implemented. The EMCS makes easy the setting connection and disconnection times in different operating periods such as holidays or special dates. Available BMSs have significant limitations on the number of different schedules that can be defined, that means they are difficult-to-use by the operator. It is necessary to be able to act on the customer with both digital and analog operations. In addition, devices capable of making decisions locally using the instructions from the server, but independent of it, must be used. It is necessary to be able to act on the customer with both digital and analog operations. The commercial element chosen to perform action is the programmable logic controller - Telemecanique Twido PLC. PLCs will obtain input signals for controlling and certificating the system, and generates the output signals for implementing control actions on the user.

- $\quad$ The EMCS manages all the acquired data and provides necessary information without additional effort from the system operator, increasing the energy efficiency in the use of the monitored buildings. The system operator does not need to wait for certain actions as the system executes them automatically once they are defined.

- Specific reports such as daily consumption or consumption by existing tariff periods are automatically generated.

\section{B. Demand response}

To improve demand response participation, the EMCS considers the following aspects:

- It may integrate all agents that can participate in demand response programs, such as the program administrator, aggregators, utilities, electrical grid operators and demand response resources. Remote control of the loads is performed using the EMCS.

- It constitutes a communication platform between the different agents (consumers, suppliers, generators, etc.), which make easier their interaction, and thus, increases the confidence in each other. This aspect is essential for the implementation of demand response programs, since it enables energy exchanging products and services in a completely dynamic way.

- Different participants can react to external variables such as energy or gas price fluctuations, restrictions on networks supply, renewable energy availability, etc., since building facilities are controlled.

\section{Demand organization}

Demand response requires the customer demand to be organized according to the specific uses or processes where the electricity is consumed. Therefore, the identification of the flexibility in the energy consumption has necessarily associated a detailed analysis, based on physical and economical concepts, of the processes in each customer facility this enables the selection of the electric appliances to be part of the DR actions [20].

The evaluation of the impact in the customer using DR resources is directly related to the "piece" of energy use that is going to be modified in the proposed operation (usually partially or totally interrupted): air conditioning, space heating lighting, etc. Therefore, in order to assess about this impact, it is required to analyze, for each end use, the relation between the service provided (heat, cold, lighting, etc.) and the electricity that is being absorbed by the process, so that the cost associated to the implementation of the DR and the degradation of the process can be evaluated.

The amount of demand required by consumers depends on the price of the electricity, so that they will only buy a "piece" of energy when the benefit obtained from using such energy is higher than the price they are willing to pay. This is illustrated in Fig. 4, which shows the case of a hotel in the north of Europe where the different load packages are organized according to the benefit obtained by the consumer [17]. Therefore, some of the consumption can be avoided or moved in the time according to the electricity prices if this option has 
for the customer a higher value than consuming this amount of energy.

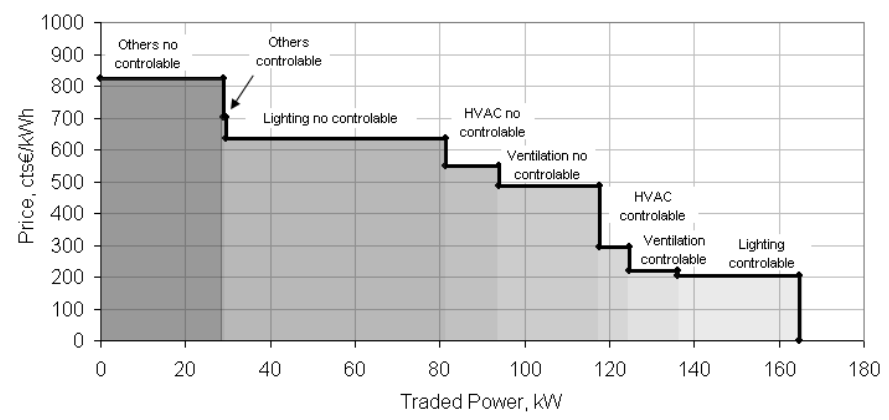

Figure 4. Example of electricity bids for the segment "Hotels"

Complementarily, consumers can offer the reduction of some packages of consumption to some agent of the market (grid operators, retailers or any other) willing to pay the price required by the customer in exchange for reducing the power demanded from the grid. In the short time, some of the consumptions can be interrupted with a very short notice time in a way that the shorter is the notice time, the higher is the price. Fig. 5 shows an example of offers curve for the segment "Offices in the south of Europe" [17].

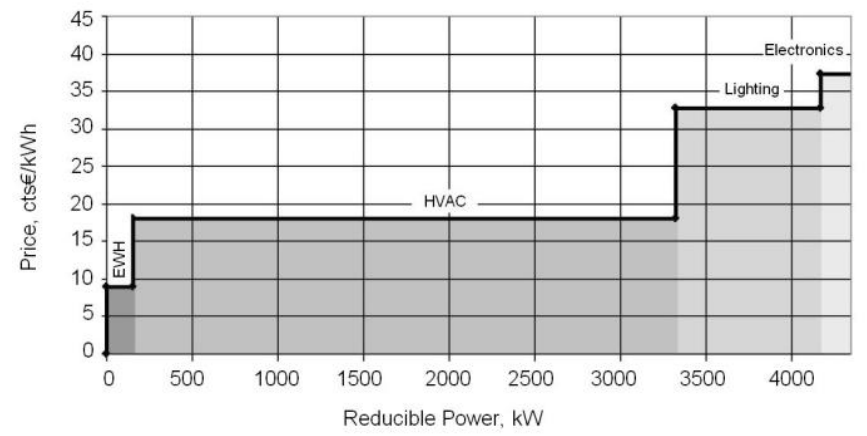

Figure 5. Example of electricity offers for the segment "Offices"

While demand response actions can take place at any time, not only during the peak period [21], their implementation could be key during peak and non-peak periods of electricity use, and are usually less costly than building more power plants [22]. Interruptions, load shifting or modification in the load shape, etc, are some of the actions that may be implemented.

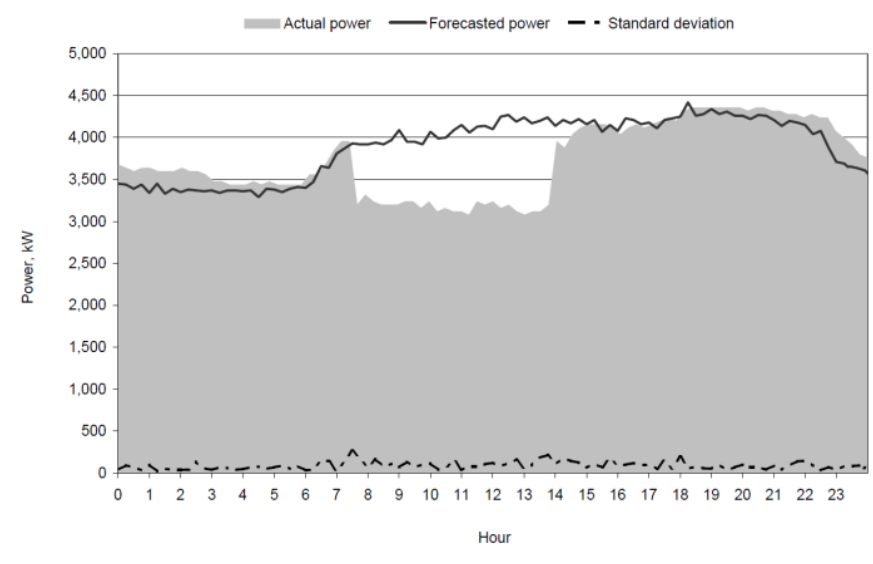

Figure 6. Load interruption performed at the UPV. April $15^{\text {th }} 2010$

A real example using the EMCS is shown in Fig. 6, which represents a real interruption performed in the Campus of the UPV in April 2010. An amount of $1 \mathrm{MW}$ was reduced from 7:00 to $14: 00$ by managing some HVAC devices, which demonstrates the high potential of this type of customers. This ability, in the context of an increasingly competitive electricity market where prices are constantly rising and the presence of renewable energy resources is gaining prominence [23], means significant benefits for both the customer and the power system.

The EMCS is already in use in other residential and industrial consumers implementing DR actions. For example, in a meat industrial customer operation of the drying lines is performed under signals of energy prices.

\section{Operation of the Micro-grid}

Together with the advantages discussed in the previous paragraphs, the EMCS introduced in this article interacts with the different elements of the micro-grid, providing them with additional functionalities to operate together and interact by following a predefined strategy. The EMCS does not substitute the existing control systems of each individual element but is complementary on them and it is able to interact with them. Consequently, existing systems keep being used for the purpose they were designed, controlling the facilities and supporting elements operation, while the EMCS integrates all together so as to create an only entity. This interaction will take place in a dedicated panel where the actions sent by EMCS shall be performed by the existing control systems, as it is shown in Fig. 7 [24].

\section{ECONOMIC AND ENVIRONMENTAL ISSUES}

\section{A. Economic Dispatch and settlement}

As described above, the energy consumed by customers comes from both the grid and the micro-grid.

The amount of power to be delivered by each one of these sources will depend on the price of electricity in order to minimize the total operating costs in the area. This task will be performed by using the economic dispatch algorithm [25]. 
The generation costs of the micro-grid resources for the hour $i$ could be represented by the following expression:

$$
C_{g-\mu}^{i}=C_{f-\mu}^{i}+C_{v-\mu}^{i} \cdot P_{g-\mu}^{i}+C_{c-\mu}^{i} \cdot\left(P_{g-\mu}^{i}\right)^{2}
$$

Similarly, the cost of the power demanded from the grid for the same hour can be assessed as:

$$
C_{g-g}^{i}=C_{f-g}^{i}+C_{v-g}^{i} \cdot P_{g-g}^{i}
$$

The incremental operating costs of generation resources of the micro-grid are:

$$
\frac{\partial C_{g-\mu}^{i}}{\partial P_{g-\mu}^{i}}=C_{v-\mu}^{i}+2 \cdot C_{c-\mu}^{i} \cdot P_{g-\mu}^{i}
$$

$$
\frac{\partial C_{g-g}^{i}}{\partial P_{g-g}^{i}}=C^{i}{ }_{v-g}
$$

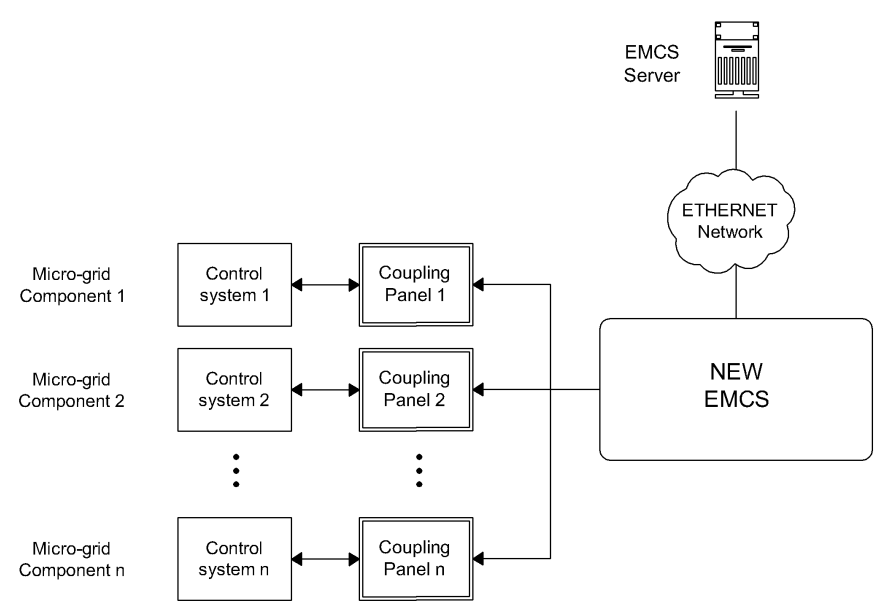

Figure 7. EMCS interaction with micro-grid components

According to the economic dispatch algorithm, the minimum total operating cost occurs when both incremental operating costs are equal [26]. Therefore, by using (3) and (4), the amount of power to be delivered by the micro-grid will be:

$$
P_{g-\mu}^{i}=\frac{C_{v-g}^{i}-C_{v-\mu}^{i}}{2 \cdot C_{c-\mu}^{i}}
$$

This result is graphically represented in Fig. 8, which shows the incremental cost curves at $7 \mathrm{pm}$ for a working day in the Universitat Politècnica de València, considering the real price of electricity in the daily pool market and the incremental cost of distributed resources as diesel generation and demand response. As it is shown in the figure, the economic dispatch occurs when the area below the incremental cost curves is minimized.

If $\mathrm{P}_{\mathrm{D}}^{\mathrm{i}}$ is the forecasted power to be demanded by the customer, the amount demanded from the grid can be calculated by the following expression:

$$
P_{g-g}^{i}=P_{D}^{i}-P_{g-\mu}^{i}
$$

After evaluating the economic dispatch for each hour, the Fig. 9 is obtained, where the amount of power from each type of grid is represented.

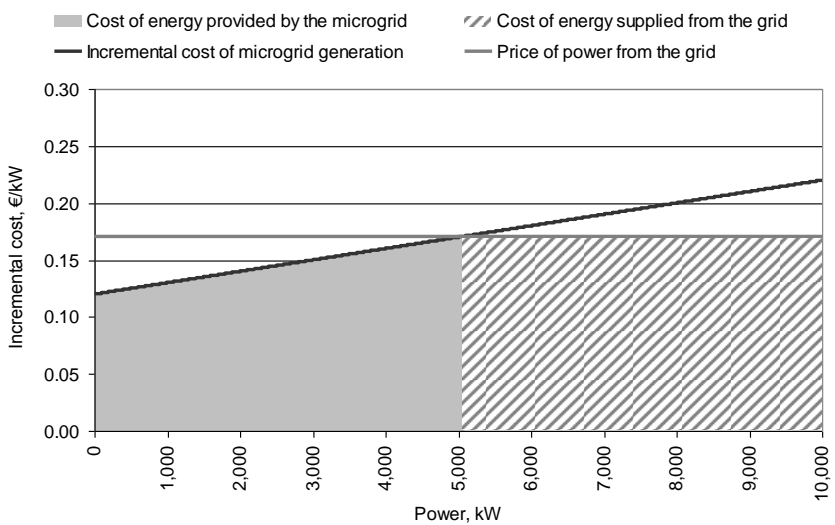

Figure 8. Results of the economic dispatch of the studied customer for the hour 19

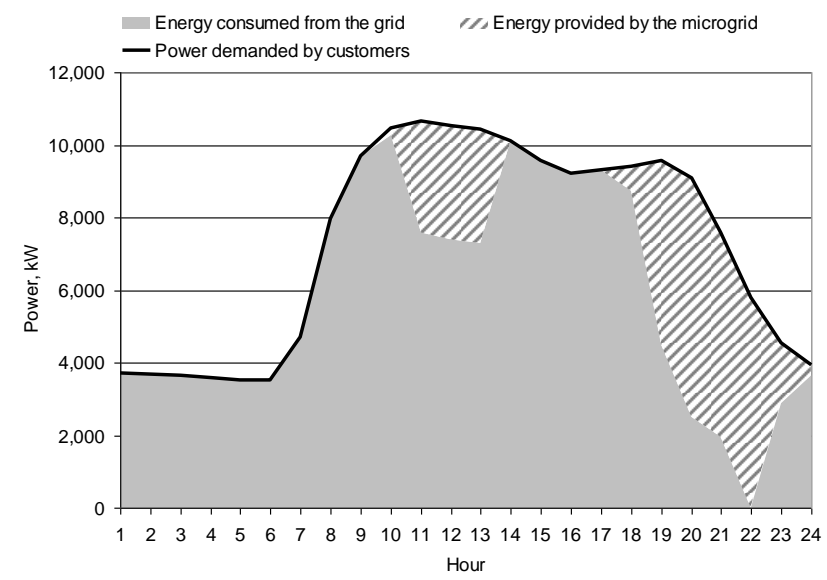

Figure 9. Distribution of energy supply between the micro-grid and the conventional grid for a typical working day of January in hourly basis: application to the demand profile of the Universitat Politèncica de València

The micro-grid includes a diesel generator whose cost, based on the experience at the UPV, has been modeled by means of the following expression: 


$$
C_{g-\mu}=10+12 \cdot 10^{-2} \cdot P_{g-\mu}+5 \cdot 10^{-6} \cdot\left(P_{g-\mu}\right)^{2}
$$

As it is shown in Fig. 9, the micro-grid will provide energy when two situations simultaneously happen: the customer is able to use the flexibility during the considered hours and the incremental cost of the micro-grid is lower than the market price

Taking into account the amount of power demanded by the customer and the hourly costs evaluated by (1) and (2), the total cost of electricity $C_{D}$ for a typical day will be calculated as follow:

$$
C_{D}=\sum_{i=1}^{24} C_{g-\mu}^{i}+\sum_{i=1}^{24} C_{g-g}^{i}
$$

According to the previous methodology, the cost of electricity at the UPV for a typical day after and before the implementation of the micro-grid has been assessed by simulation, resulting in savings of $784.14 € /$ day, that means $4.03 \%$ in the total cost of electricity.

The methodology herby presented enables not only evaluate the technical and economical impact, but also an environmental assessment about the emissions avoided to be emitted into the atmosphere when the power supplied from the micro-grid or the flexibility of the customer are used, as presented in the next subsection.

\section{B. Environmental evaluation}

Avoided atmospheric emissions can be assessed by using the methodology proposed in [27], where the coefficients which calculate the amount of $\mathrm{CO}_{2}$ per MWh emitted in each time period are considered. Those factors may differ depending on the power generation mix at the time under consideration. As an example, the factors used in Spain for each period of time are shown in Table I

The emission factor for the on-peak period is usually higher than for the rest of periods since the most inefficient technologies are supplying energy at these hours (coal and fuelgas), and a higher amount of $\mathrm{CO}_{2}$ is emitted into the atmosphere.

Avoided emissions $\left(A E_{s}\right)$ when demand is reduced or shifted to a different period can be calculated by means of the following equation:

$$
A E_{s}=\sum_{k=1}^{3} E_{1}^{k} \cdot f e_{k}-\left[\sum_{k=1}^{3} E_{2}^{k} \cdot f e_{k}+\sum_{k=1}^{3} E_{3}^{k} \cdot f e_{k}\right]
$$

where $f e_{i}$ are the emissions factors for each period " $i$ ": onpeak, shoulder and valley.
TABLE I. EMISSION FACTORS FOR DIFFERENT PERIODS IN SPAIN

\begin{tabular}{|c|c|}
\hline Period & $\begin{array}{c}\text { Emission factor } f \boldsymbol{e}_{\mathbf{k}} \\
(\mathbf{t C O} / \mathbf{M W h})\end{array}$ \\
\hline On peak & 0.750 \\
\hline Shoulder & 0.649 \\
\hline Valley & 0.517 \\
\hline \multicolumn{2}{|c|}{ Source: Spanish Departments of Industry and Housing }
\end{tabular}

In the example of the UPV, the avoided emissions if the electricity was provided by the micro-grid by means of clean generation resources (renewable and demand response) would be about 25.6 tonCO $/$ day, that means about the $22.4 \%$ regarding the initial value of the amount of emitted $\mathrm{CO}_{2}$.

\section{CONCLUSIONS}

A novel approach about the management of micro-grids is presented in this paper, integrating the electricity supplied from the grid with the use of own renewable generation, more efficient resources, and demand resources connected to the micro-grid by means of an EMCS.

The proposed integral system provides existing control systems with new functionalities, not only controlling the facilities, but also improving the energy management by means of demand side integration and adequate tools to manage the micro-grid, integrating the different participating components.

The effectiveness of the actions proposed in this paper is evaluated by means of a method, which is also presented, to assess their economic and environmental effect. The particular case of the Campus of Vera of the Universitat Politècnica de València is analyzed, resulting in significant savings higher than $4 \%$ when part of the electricity supply comes from own resources from the micro-grid, properly managed by means of the EMCS. Similarly, reductions of about $22 \%$ in the $\mathrm{CO}_{2}$ emissions have been assessed in periods when own renewable generation resources and demand management is cheaper than the electricity provided by the grid.

\section{REFERENCES}

[1] R.H. Lasseter and P. Piagi: "Extended Microrred Using (DER) Distributed Energy Resources". Power Engineering Society General Meeting, 2007. IEEE24- 28 June 2007 Page(s): 1 - 5

[2] Yunwei Li, D.M. Vilathgamuwa and Poh Chiang Loh: "Design, analysis, and realtime testing of a controller for multibus microrred system". Power Electronics, IEEE Transactions on Volume 19, Issue 5, Sept. 2004 Page(s): 1195 - 1204

[3] A.L. Dimeas, A.L and N.D. Hatziargyriou: "Operation of a Multiagent System for Microrred Control". Power Systems, IEEE Transactions on Volume 20, Issue 3, Aug. 2005 Page(s): 1447 - 1455

[4] J.A.P. Lopes, C.L. Moreira, C.L. and A.G. Madureira: "Defining control strategies for Microrredes islanded operation". Power Systems, IEEE Transactions on Volume 21, Issue 2, May 2006 Page(s):916 - 924

[5] H. Nikkhajoei and R.H. Lasseter: "Microrred Protection". Power Engineering Society General Meeting, 2007. IEEE 24-28 June 2007 Page(s): $1-6$

[6] E. Ghiani, S. Mocci and F. Pilo: "Optimal reconfiguration of distribution networks according to the microrred paradigm”. Future Power Systems, 2005 International Conference on16-18 Nov. 2005 Page(s):6 pp 
[7] N. Jayawarna, S. Wu, Y. Zhang, N. Jenkins and M. Barnes: "Stability of a Microrred". Power Electronics, Machines and Drives, 2006. The 3rd IET International Conference on Mar. 2006 Page(s):316 - 320

[8] N.D. Hatziargyriou, A. Dimeas, A.G. Tsikalakis, J.A. Pecas Lopes, G. Kariniotakis, G. and J. Oyarzabal: "Management of Microrredes in Market Environment". Future Power Systems, 2005 International Conference on 16-18 Nov. 2005 Page(s): 1 - 7

[9] J. Kennedy, B. Fox and D.J. Morrow: "Distributed generation as a balancing resource for wind generation". Renewable Power Generation, IET Volume 1, Issue 3, September 2007 Page(s): 167 - 174

[10] C. Marnay, G. Venkataramanan, M. Stadler, M. A. Siddiqui, R. Firestone and B. Chandran: "Optimal Technology Selection and Operation of Microrredes in Commercial Buildings". 67 Power Engineering Society General Meeting, 2007. IEEE 24-28 June 2007 Page(s): 1 - 7

[11] A. Amorim, A.L. Cardoso, J. Oyarzabal and N. Melo: "Analysis of the Connection of a Microturbine to a Low Voltage Grid". Future Power Systems, 2005 International Conference on 16-18 Nov. 2005 Page(s):1 5

[12] Y. Kojima, M. Koshio, S. Nakamura, H. Maejima, Y. Fujioka and T. Goda: "A Demonstration Project in Hachinohe: Microrred with Private Distribution Line". System of Systems Engineering, 2007. SoSE '07. IEEE International Conference on 16-18 April 2007 Page(s): 1 - 6

[13] S. Rassanti, V. Smith and B. Wilson: "Controlling market power and price spikes in electricity networks: Demand-side bidding". Interdisciplinary centre for economic science, George Mason University, July 2001

[14] D.S. Kirschen: "Demand-side view of electricity markets". IEEE trans. power systems, vol. 18, pp. 520-527, mayo 2003

[15] R. Cowart: "Efficient reliability, the critical role of demand-side resources in power systems and markets". The national association of regulatory utility commissioners, junio 2001

[16] ICF Consulting. 2002. "Economic assessment of RTO policy Report". FERC, mayo 2002

[17] C. Álvarez, A. Gabaldón and A. Molina: "Assessment and simulation of the responsive demand potential in end-user facilities: Application to a university customer". IEEE trans. power systems, núm. 19, pp. 12231231, 2004.
[18] European Commission, 2003, "New ERA for electricity in Europe". Directorate General for Research

[19] G. Escrivá, M. Alcázar, C. Alvarez. "Integral management system for the energy efficiency improvement in commercial facilities: Application to the Polytechnic University of Valencia". International conference on renewable energy and power quality (ICREPQ'09), April 2009.

[20] C. Álvarez Bel, M. Alcázar Ortega, G. Escrivá Escrivá, A. Gabaldón Marín: "Technical and economical tools to assess customer demand response in the commercial sector". Energy Conversion and Management, Volume 50, Issue 10, October 2009, pages 2605-2612.

[21] The Federal Energy Regulatory Commission Staff: Draft for Comment of the National Action Plan on Demand Response. March; 2010. $\langle$ http://www. ferc.gov>.

[22] Chiu A, Ipakchi A, Chuang A, Qiu B, Brooks D, Koch E, et al., Framework for Integrated Demand Response (DR) and Distributed Energy Resources (DER) Models. NAESB \& UCAlug. September; 2009. 〈http://osgug.ucaiug.org>.

[23] M. Alcázar-Ortega, C. Álvarez-Bel, G. Escrivá-Escrivá, A. Domijan. "Evaluation and assessment of demand response potential applied to the meat industry". Applied Energy, Volume 92, April 2012, Pages 84-91

[24] G. Escrivá-Escrivá, I. Segura-Heras, M.Alcázar-Ortega: “Application of an energy management and control system to assess the potential of different control strategies in HVAC systems". Energy and Buildings, Volume 42, Issue 11, November 2010, Pages 2258-2267

[25] J. Glover, M. Sarma and T. Overbye: "Power systems: analysis and design". Thompson Corporation. Toronto, 2008.

[26] O. Elgerd: "Electric energy systems: theory and introduction". McGrawHill, New York, 1982.

[27] M. Alcázar-Ortega: "Evaluation and assessment of new demand response programs based on the use of flexibility in industrial processes: Application to the food industry". Ph.D. Dissertation. University of South Florida and Universidad Politécnica de Valencia. February, 2011. 